\title{
STANDING AND WALKING
}

It is wise to seek

professional

advice before

choosing from the

wide range of

walking aids

available, says Sue

Martin.

USEFUL INFORMATION

\section{Disability Information \\ Trust}

Mary Marlborough Centre

Nuffield Orthopaedic

Centre NHS Trust

Headington

Oxford OX3 7LD

Publishes a useful

equipment guide,

'Walking aids',

price $£ 4.50$ post free

\section{Disabled Living \\ Foundation}

380-384 Harrow Road

London W9 $2 \mathrm{HU}$

Tel: 01712896111

Produces a product guide on standing and walking, price $£ 8$
A wide range of walking equipment is available, from simple wooden sticks to more sophisticated, wheeled mobility devices.

\section{WALKING STICKS}

Walking sticks may be adjustable or sawn off to size. Measurement for length is from the user's wrist to the floor. Some walking sticks have shaped handles for comfort. They are useful for people with painful hands, for example because of arthritis.

\section{CRUTCHES}

These are either axillary or elbow support. Axillary crutches (going under the arm) are made of wood and can be adjusted for overall length and hand position. They are padded under the arm to protect nerves and blood vessels from pressure. More frequently prescribed nowadays are adjustable metal elbow crutches. Crutches offer more stability than walking sticks. They are used by people who must not put weight through an injured (e.g. fractured) leg. They must be provided in pairs. Weight must be taken through the hands and not under the arms.

\section{WALKING FRAMES}

Walking frames are made of metal and can be of fixed height or adjustable. They may or may not have wheels. Frames are more frequently used by older people, who may be frail and afraid of falling.

\section{ROLLATORS}

These are a type of frame with wheels and handles for pushing. The wheels may move in one direction or swivel. Swivel wheels will improve manoeuvrability, but the user may be less stable. The three-wheeled rollator is very popular. It is narrow and highly manoeuvrable and, therefore, useful in restricted spaces. Trolleys are sometimes used indoors and have the advantage of transporting goods from place to place.

\section{OUTDOOR WALKING EQUIPMENT}

This has seen an increase in variety over recent years. Nearly all types have four wheels, swivel or unidirectional, and tend to be larger and more robust. Many offer such accessories as a basket, tray or inbuilt seat. They are more expensive and, therefore, more difficult to obtain from statutory providers.

\section{ASSESSMENT}

It is advisable to seek professional guidance before using any walking aid. Factors to be considered include pain, safety, fear of falling, mobility and function.

The assessor may be a doctor, physiotherapist, occupational therapist or nurse. They will need to know the diagnosis and expected prognosis, physical and functional status. It is important to have details of the environment in which the equipment is to be used.

Training in the use of the walking aid is necessary. Users need to be taught how to get up and down stairs, and into and out of a sitting position. Where possible, normal walking patterns should be maintained. Safety is of paramount importance. 